\title{
Mental Traveling Along Psychological Distances: The Effects of Cultural Syndromes, Perspective Flexibility, and Construal Level
}

\author{
Vincent Chi Wong and Robert S. Wyer Jr. \\ The Chinese University of Hong Kong
}

\begin{abstract}
Individuals' psychological distance from the stimuli they encounter in daily life can influence the abstractness or generality of the mental representations they form of these stimuli. However, these representations can also depend on the perspective from which the stimuli are construed. When individuals have either an individualistic social orientation or a short-term temporal orientation, they construe psychologically distal events more globally than they construe proximal ones, as implied by construal level theory (Trope \& Liberman, 2010). When they have either a collectivistic social orientation or a long-term temporal orientation, however, they not only construe the implications of distal events more concretely than individuals with an egocentric perspective but also construe the implications of proximal events in more abstract terms. These effects are mediated by the flexibility of the perspectives that people take when they make judgments. Differences in perspective flexibility account for the impact of both situationally induced differences in social and temporal orientation and more chronic cultural differences in these orientations.
\end{abstract}

Keywords: individualism/collectivism, short-/long-term orientation, perspective flexibility, psychological distance, construal level

People comprehend the natural and social world by constructing mental representations of the objects and events they encounter (Bruner, 1957). A conceptualization proposed by Trope and Liberman (2003, 2010), known as construal level theory, describes how this is done. The theory specifies the manner in which psychological distance from an event (which can be temporal, social, spatial, or probabilistic) affects the abstractness or generality of the concepts they typically apply in construing its implications. That is, psychologically distal stimuli are represented in terms of global concepts that refer to central, intrinsic features, whereas psychologically proximal stimuli are comprehended in terms of more concrete concepts that often refer to peripheral, context-specific attributes (Trope, Liberman, \& Wakslak, 2007).

Construal level theory implicitly assumes that people construe the implications of information they receive from the perspective of themselves and the "here and now" (Bar-Anan, Liberman, \& Trope, 2006; Liberman \& Trope, 2008). Consequently, people assess the psychological distance of objects and events in relation to this egocentric perspective (for a discussion of nonegocentric distance, see Liberman \& Förster, 2009; Yan, 2014). Thus, as the

Vincent Chi Wong and Robert S. Wyer Jr., Department of Marketing, The Chinese University of Hong Kong.

This research was supported in part by Research Grant Council of the Hong Kong Special Administrative Region, China (Project CUHK 452813). This article is based on the doctoral dissertation of the first author under the supervision of the second author at The Chinese University of Hong Kong.

Correspondence concerning this article should be addressed to Vincent Chi Wong, Department of Marketing, The Chinese University of Hong Kong, Cheng Yu Tung Building, Chak Cheung Street, Shatin, New Territories, Hong Kong. E-mail: vincentchiwong@gmail.com distance of a stimulus from this reference point increases, the concepts people use to comprehend it and construe its implications become more abstract and global.

The assumption that individuals evaluate information from an egocentric perspective may be of limited generality, however (e.g., Chen et al., 2014; Kross \& Grossmann, 2012; Kross et al., 2014). People do not always construe the implications of information with reference to themselves and their immediate surroundings. Rather, they often mentally "travel" to another time, place, or person and construe the implications of information from this allocentric point of view. Perceiving temporal distance from an allocentric reference point might lead people to imagine future events as more imminent than they otherwise would (Zimbardo \& Boyd, 1999). Likewise, perceiving social distance from such a perspective (i.e., putting themselves in others' shoes) might lead people to imagine not only what others are experiencing but also how they might personally appear to these individuals (e.g., Libby, Shaeffer, \& Eibach, 2009).

Although most people have the ability to take an allocentric perspective (Gopnik \& Wellman, 1992), they may differ in their disposition to do so (Christian, Miles, Parkinson, \& Macrae, 2013; Wu \& Keysar, 2007). However, the implications of this disposition for the construal of socially and temporally constrained events (i.e., events that occur at a particular time and pertain to a specific person) have received little attention (Soderberg, Callahan, Kochersberger, Amit, \& Ledgerwood, 2015). The present research examined these implications.

The disposition to construe events from different reference points can be conceptualized as perspective flexibility. All persons may spontaneously interpret an event with reference to themselves at the time they first receive information about it. However, whereas some individuals maintain this egocentric perspective when they construe the event's implications for a judgment, others 
shift to an allocentric perspective. This flexibility, which is presumably acquired through learning, can often be traced to social and cultural norms that reinforce perspective switching. In this regard, (Hofstede 1991, 2001; De Mooij \& Hofstede, 2011) and Triandis (1995) have identified cultural differences in both individuals' social orientation and their temporal orientation. A collectivistic (vs. individualistic) social orientation increases people's tendency to take others' goals and needs into account rather than focusing on themselves alone. A long-term (vs. short-term) temporal orientation encourages people to focus on the past and future in addition to their immediate life circumstances (Bearden, Money, \& Nevins, 2006; Hofstede \& Bond, 1988). Although chronic cultural and individual differences in these orientations can exist, situational factors are likely to influence their accessibility and use as well (Oyserman, Coon, \& Kemmelmeier, 2002).

Our conceptualization of the effects of these orientations is conveyed in Figure 1. We speculated that although a collectivistic social orientation and a long-term temporal orientation have different antecedents (Chinese Culture Connection, 1987), both orientations increase perspective flexibility and consequently dispose individuals to take an allocentric perspective when they construe the implications of a social event. To this extent, they lead people to construe the implications of distal events more concretely, but to construe proximal events in more abstract terms, than persons with individualistic social or short-term temporal orientations. The conceptual underpinnings of these findings are elaborated in the next section.

\section{Theoretical Background}

\section{Psychological Distance and Level of Construal}

People can construe an object or event at different levels of abstractness or generality. A low-level construal conveys specific features of a stimulus, the implications of which are often context specific, whereas a high-level construal conveys a more global, de-contextualized representation of the stimulus. According to construal level theory (Trope \& Liberman, 2003, 2010), people use increasingly high levels of construal to represent an object as their psychological (i.e., temporal, social, spatial or probabilistic) distance from the object increases. For example, people who plan to rent an apartment a year from now may focus on its living space and facilities. If people are looking for accommodations next week, however, they give more weight to the availability and moving expenses (Kim, Park, \& Wyer, 2009). Thus, if the global and concrete features of a stimulus differ in desirability, evaluations of the apartment at different points in time might appear to be inconsistent (e.g., Zhao, Hoeffler, \& Zauberman, 2007).

Construal level theory implicitly assumes that psychological distance is egocentric (Trope \& Liberman, 2010; but see Liberman \& Förster, 2009; Yan, 2014) and that distances along different dimensions have a common meaning (that is, they all reflect a divergence from direct experience; Kim, Zhang, \& Li, 2008). People might often access this common meaning automatically, independently of the dimension they happen to be considering. Consequently, the interpretation of a stimulus along one dimension can affect its interpretation along others (Yan, 2014; but see Zhang \& Wang, 2009).

\section{General Effects of Perspective}

Perspective is often a necessary feature of the representation that is formed of social events (Davis, Conklin, Smith, \& Luce, 1996; Kross \& Grossmann, 2012). When individuals receive information about an event that occurs at a particular time and place, they theoretically construct a mental simulation of it, or a situation model (Radvansky \& Zacks, 1991; Wyer \& Radvansky, 1999). This representation has a visual image component and thus, like a picture, is constructed from a particular perspective (Wyer, 2003; Wyer \& Radvansky, 1999). When individuals first receive information about an event, the situation model they form of it contains a visual image that is viewed from the perspective of themselves as an observer (Wyer \& Radvansky, 1999). If they are called upon to consider the implications of the event for a judgment or decision, however, they may shift their perspective and construe its implications from a more remote vantage point (Goldstein, Vezich, \& Shapiro, 2014; Zimbardo \& Boyd, 1999).

Although previous research on construal level has typically not considered the effects of taking a perspective other than one's own, these effects are quite evident in other domains of inquiry (for a recent review, see Goldstein et al., 2014). The disposition to "transport" oneself into a story, and imagine the situation from the perspective of the protagonists is common in the construction of narratives (Escalas, 2007; Green \& Brock, 2000). Requests for

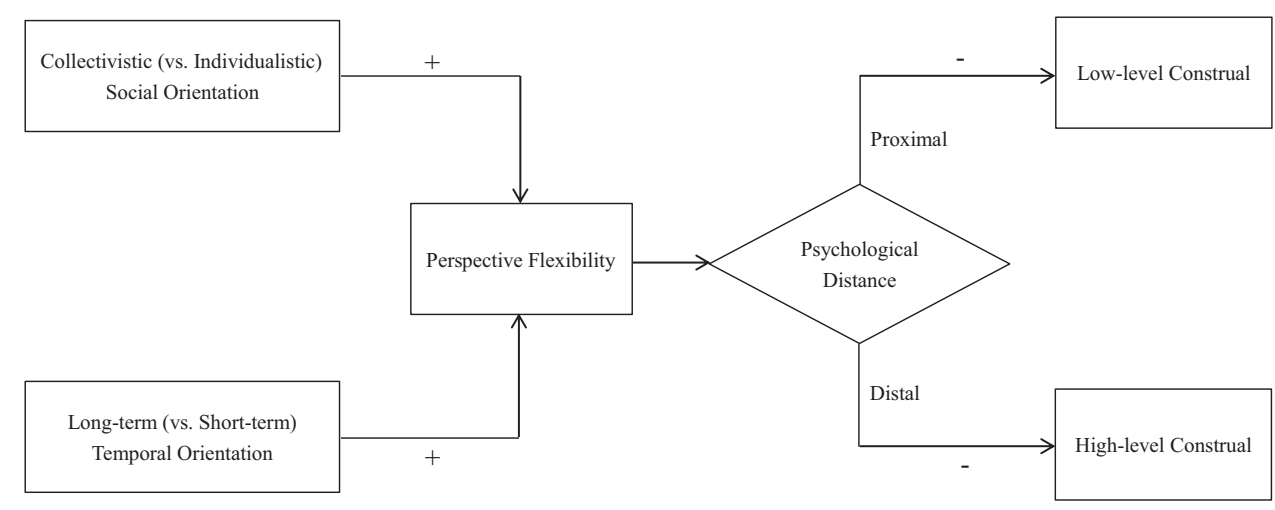

Figure 1. Conceptual model of the effects of temporal and social orientation on construal level. 
money to help victims of misfortune often urge recipients to imagine themselves in the situation confronting the victims (Hung \& Wyer, 2014; Jones \& Nisbet, 1972; Sujan, Bettman, \& Baumgartner, 1993) and advertisements often encourage consumers to imagine themselves using the product being promoted (McFerran, Dahl, Gorn, \& Honea, 2010). Appeals to take action to prevent a future event (e.g., global warming) often urge individuals to imagine themselves at the point in time at which the events are likely to occur (Milfont \& Gouveia, 2006).

Taking an allocentric perspective when imagining a distal event can make the event seem more immediate or "self-like" (Epley, Caruso, \& Bazerman, 2006; Epley, Keysar, Van Boven, \& Gilovich, 2004; Galinsky \& Moskowitz, 2000). As a result, the event is likely to be construed at a more concrete level than it would be if an egocentric perspective were taken. When an event involves oneself in the here and now, however, taking an allocentric perspective leads the event to be viewed from a distance (Ayduk \& Kross, 2008; Kross \& Ayduk, 2008; Kross, Ayduk, \& Mischel, 2005) and this results in a higher level of construal than would otherwise be the case.

\section{Determinants of Perspective Shift}

In much of the aforementioned research, participants were explicitly or implicitly requested to consider an event's occurrence at a future point in time or to imagine it occurring to someone other than themselves. However, the factors that influence the disposition to shift perspectives when making judgments of an event have rarely been considered. We conceptualized the disposition to shift to an allocentric perspective when comprehending an observed or imagined event as perspective flexibility, and considered two factors that are likely to affect this disposition: social orientation and temporal orientation.

Collectivistic versus individualistic social orientation. Cultural and individual differences exist along a dimension of individualism versus collectivism (Hofstede, 1991; Oyserman \& Lee, 2008; Oyserman \& Sorensen, 2009; Triandis, 1995). People with an individualistic orientation consider themselves to be independent of others, whereas those with a collectivistic orientation are more inclined to think of themselves as part of a group or collective to which they belong. Thus, collectivists are typically more sensitive to others' feelings and needs than individualists are (Singelis, Triandis, Bhawuk, \& Gelfand, 1995) and are relatively more likely to construe the implications of social situations from the perspective of others (Cohen \& Gunz, 2002).

Many studies (e.g., Brewer \& Gardner, 1996; Kitayama, Markus, Tummala, Kurokawa, \& Kato, 1990; Ross, Xun, \& Wilson, 2002; Wu \& Keysar, 2007) have identified cultural differences in the perspective that people take when they construe events. In a study by Cohen and Gunz (2002), for example, participants imagined a situation in which they were the center of attention. Americans (who are typically individualistic) described the event from a first-person perspective whereas Chinese (who are typically collectivistic) were more likely to describe it from a third person's perspective. Both this and other research (Cohen \& Gunz, 2002; Ross et al., 2002) suggest that a collectivistic orientation encourages a shift to an allocentric perspective, even in the absence of external requirements to do so.
Although chronic collectivistic and individualistic orientations can be the result of persons' cultural background, they can also be situationally induced (Lee, Aaker, \& Gardner, 2000; for reviews, see Oyserman \& Lee, 2008; Oyserman \& Sorensen, 2009). For example, these orientations can be activated by inducing individuals to use first-person singular or first-person plural pronouns in an irrelevant task (e.g., Gardner, Gabriel, \& Lee, 1999; Kemmelmeier, 2003; Kühnen \& Oyserman, 2002; Trafimow, Triandis, \& Goto, 1991; Vohs \& Heatherton, 2001), or by asking them to list similarities or differences between themselves and others (Holland, Roeder, Van Baaren, Brandt, \& Hannover, 2004; Kühnen, Hannover, \& Schubert, 2001; Ybarra \& Trafimow, 1998). In the studies we report, we considered both chronic cultural differences and situationally induced differences in these orientations.

Short-term versus long-term temporal orientation. A second determinant of individuals' perspective flexibility may be their temporal orientation. Hofstede and Bond (1988) found that East Asians are more likely than members of Western countries to have a long-term temporal orientation as reflected in the importance they attach to future goals and values. Individuals with a long-term temporal orientation value the past and future rather than only the here and now (Bearden et al., 2006).

People with a long-term temporal orientation are willing to delay short-term goal attainment in order to prepare for the future (Beldona, Inkpen, \& Phatak, 1998; Brislin \& Kim, 2003). For example, they are likely to focus on future achievement and to engage in frugal behavior (Bearden et al., 2006; Lastovicka, Bettencourt, Hughner, \& Kuntze, 1999). Thus, whereas individuals with a short-term orientation use the here and now as a referent, those with a long-term orientation are likely to consider situations from a future perspective as well. Differences in temporal orientation can be chronic but can also be situationally activated (Kopalle, Lehmann, \& Farley, 2010).

\section{Effects of Perspective Flexibility}

Because individuals' social orientation and their temporal orientation are likely to have different antecedents, they may be uncorrelated. However, they could independently affect perspective flexibility and consequently the disposition to shift perspectives when construing the implications of social events. Inflexible individuals are likely to maintain an egocentric perspective when construing the implications of an event regardless of the nature of this event, whereas flexible persons are likely to shift to an allocentric point of view. This has two implications. First, flexible individuals are more likely than inflexible individuals to shift their perspective toward a distal event, seeing it as less remote than inflexible individuals do. At the same time, they are also more inclined to take an allocentric perspective when an event concerns themselves and the here and now, judging it as more distant than they would if they took an egocentric perspective.

If this is so, individuals' social and temporal orientations are likely to influence the construal of social events through the mediating impact of these orientations on perspective flexibility. That is, collectivists are likely to construe socially distal events more concretely but proximal events more abstractly than individualists do. Correspondingly, individuals with a long-term temporal orientation should construe temporally distal event more concretely but proximal events more abstractly than those with a 
short-term orientation. Moreover, although the two orientations may not be directly related, activating one of these orientations could induce a behavioral mindset (Wyer \& Xu, 2010; Wyer, Xu, \& Shen, 2012) that, once triggered, influences the disposition to shift perspectives along not only the dimension to which it directly pertains but other dimensions as well. In this regard, other studies have found that collectivists are more aware of the indirect, distal consequences of events than individualists are (Maddux \& Yuki, 2006). Moreover, people often treat their future self as if it were another person (Pronin, Olivola, \& Kennedy, 2008). Our research provides further evidence of these cross-dimensional effects.

\section{The Present Research}

The implications of our discussion in the preceding section are summarized in Figure 1. Individuals may spontaneously comprehend descriptions of events by constructing a situation model of the event from an egocentric perspective. When they are called upon to make a judgment or decision to which the event is relevant, however, both collectivists and persons with a long-term temporal orientation, who have flexible perspectives, are likely to shift to an allocentric perspective, and this may be true for both psychologically distant events and psychologically proximal ones. This perspective should affect the level at which they construe the events' implications.

To investigate these effects, we employed a paradigm often used in research on construal level theory to assess the effects of psychological distance (Kim et al., 2008; Liberman \& Trope, 1998; Trope \& Liberman, 2003; Yan \& Sengupta, 2011). Participants were asked to consider a socially or temporally constrained action (e.g., renting an apartment). In some studies, we varied the time at which the action was considered (e.g., immediately or distal future). In other studies, we varied the person involved in the action (oneself or a stranger). The favorableness of high-level (e.g., desirability-related) features and low-level (e.g., feasibilityrelated) features of the action were varied. Thus, the level at which the action was construed could be inferred from the relative weight that was given to the two sets of features when making a judgment.

An initial study (Experiment 1) showed that perspective flexibility affected the construal of temporally proximal and temporally distant events in the manner we hypothesized. Two other experiments investigated the interactive effects of (a) temporal orientation and temporal distance (Experiment 2), and (b) social orientation and social distance (Experiment 3 ) on construal level. These experiments also confirmed the mediating effects of perspective flexibility. Two additional experiments (Experiments 4 and 5) evaluated our expectations that the effects of social orientation and temporal orientation did not depend on the dimension of distance being varied. Experiment 6 directly compared how members of Western and Asian cultures differed in perspective flexibility and therefore the manner in which they mentally represented temporally proximal and distant events. Experiment 6 also extended the findings to temporally constrained categorization processes, showing that individuals differing in social orientation differed in the breadth of their categorization of stimulus items in the way we predicted.

A final experiment addressed a central assumption of our theory. Our conceptualization of the role of perspective flexibility assumes that individuals who receive information about an event first comprehend the information from an egocentric perspective and then, if they have perspective flexibility, shift their perspective to a more allocentric point of view when they construe its implications for a judgment. An alternative possibility, however, is that individuals with a collectivistic orientation or a long-term temporal orientation take an allocentric perspective directly without engaging in a shift in perspective. To this extent, perspective flexibility would not be a necessary precondition of the effects we predicted. Thus, Experiment 7 evaluated this possibility.

\section{Experiment 1}

\section{Effects of Perspective Flexibility and Temporal Distance}

Experiment 1 tested the effects of perspective flexibility on the construal of psychologically close and distant event and the consequent evaluations of these events. Participants whose perspective flexibility was experimentally manipulated were asked to consider renting an apartment either immediately or in the future (Kim et al., 2009; Liberman \& Trope, 1998). The apartment was described in terms of both favorable intrinsic features and unfavorable context-specific features. We expected that inflexible participants would consider the situation from an egocentric perspective and would report a greater intention to rent the apartment in the future than to rent it immediately. However, we expected that flexible participants would take an allocentric perspective in both cases and, therefore, would report not only less intention to rent the apartment in the future than inflexible participants would but also greater intention to rent it immediately than the latter.

\section{Method}

Participants and design. One hundred eight bilingual Hong Kong undergraduate students $\left(M_{\text {age }}=20.29\right)$ participated in the study for HK\$40 (about US\$5). They were randomly assigned to cells of a 2 (Perspective Flexibility: inflexible vs. flexible) $\times 2$ (Temporal Distance: immediate vs. future) between-subjects design.

Procedure. Participants were told they would take part in two unrelated tasks. To manipulate participants' perspective flexibility, we first asked them to perform a "defense game" for the ostensible purpose of assessing their debating ability. Specifically, participants read the details of a flight delay case that described a conflict among three parties: the airport, the airline company, and the passengers. The case (see Appendix A) was described in such a way that the responsibility could rest with all three parties. After learning about the case, participants in the inflexible perspective condition were instructed:

Imagine that you are a spokesperson for the airport (airline; passengers) and are responsible for defending your position. Write a paragraph explaining as forcefully as possible why you were not to blame for the situation that occurred and should not be held responsible for it. Be as persuasive as possible in supporting your position.

In contrast, participants in the flexible perspective condition were told:

Imagine you are a mediator sent from National Aviation Administration to reconcile this conflict, and need to understand the perspective 
of each party (the airport administration, the airline company, and the passengers) and convey their positions in as evenhanded a way as possible. Write a paragraph stating why you think each party was not entirely to blame and should not be held responsible. Be as fair to each party as possible in preparing your statement.

After participants had written for $5 \mathrm{~min}$, we asked them to perform an ostensibly unrelated task to determine how people process information and make judgments. Specifically, participants received information about an apartment with favorable desirability-related features (i.e., large living space and readymade furniture) but unfavorable situation-specific features (i.e., inflexible moving in date and high moving expense; see Appendix $\mathrm{B}$ for a description of the apartment). (The implications of the features were confirmed in a separate pretest.) Participants were asked to consider the likelihood of renting the apartment either "now" or "1 year later" along a scale from 1 (very unlikely) to 9 (very likely).

Finally, participants responded to two sets of questions. One set of two questions concerned the flexibility of the perspective they took in the defense game ("To what extent did you take every party's perspective when you wrote down the paragraph?" and "To what extent did you put yourself in every party's shoes when you wrote down the paragraph?"). Four other questions, which were borrowed from Ben-Itzhak, Bluvstein, and Maor's (2014) Psychological Flexibility Scale, measured general perspective flexibility ("I recognize myself as someone who is able to change my position and modify accordingly," "When I encounter difficulties in achieving a goal, I am able to try numerous different solutions," "I think of myself as a person who is attentive to a variety of different messages and ideas," "Concepts may possess different meanings when perceived in different contexts"). Responses to both sets of questions, along scales from 1 (not at all) to 9 (very much), were highly reliable ( $\alpha=.67$ and $\alpha=.83$, respectively) and were averaged separately.

\section{Results}

Manipulation check. Participants reported being more flexible in flexible perspective conditions than in inflexible perspective conditions, and this was true both in the arbitration task $(M=6.34$, $S D=1.20$ vs. $M=5.61, S D=1.56$, respectively), $F(1,104)=7.27$, $p=.008, \eta_{\mathrm{p}}^{2}=.065$, and more generally $(M=6.47, S D=.79 \mathrm{vs}$. $M=6.06, S D=1.16$, respectively), $F(1,104)=4.34, p=.040$, $\eta_{\mathrm{p}}^{2}=.040$. No effects involving temporal distance were significant in either analysis $(F \mathrm{~s}<1, n s)$. Thus, temporal distance did not lead to an observable shift in perspective.

Intention to rent. Table 1 summarizes participants' intention to rent the desirable but nonfeasible apartment as a function of perspective flexibility and temporal distance. Consistent with previous findings (Liberman \& Trope, 1998), participants evaluated the apartment more favorably when they considered it for the future $(M=6.12, S D=1.45)$ than when they considered it for immediate use $(M=5.14, S D=1.65), F(1,104)=11.24, p=$ $.001, \eta_{\mathrm{p}}^{2}=.098$, suggesting that they weighted desirability-related features more heavily in the former case. However, the interaction of temporal distance and perspective flexibility was also significant, $F(1,104)=9.51, p=.003, \eta_{\mathrm{p}}^{2}=.084$, and indicated that the effect of temporal distance was only evident among participants with an inflexible perspective (6.67 vs. 4.81 , for future and imme-
Table 1

Intention to Rent a Desirable But Infeasible Apartment as a Function of Perspective Flexibility and Temporal Distance: Experiment 1

\begin{tabular}{lcc}
\hline & \multicolumn{2}{c}{ Temporal distance } \\
\cline { 2 - 3 } Perspective & \multicolumn{1}{c}{ Now } & 1 Year later \\
\hline Inflexible & $4.81^{\mathrm{a}}(1.61)$ & $6.67^{\mathrm{b}}(1.35)$ \\
Flexible & $5.54^{\mathrm{a}, \mathrm{c}}(1.64)$ & $5.62^{\mathrm{c}}(1.37)$ \\
\hline
\end{tabular}

Note. $\quad N=108$. Standard deviations are given in parentheses. Cells with unlike superscripts in each row and column differ at $p \leq .05$.

diate consideration, respectively), $F(1,104)=21.65, p<.001$, $\eta_{\mathrm{p}}^{2}=.172$, and was not evident among those with a flexible perspective ( 5.62 vs. 5.54 , for future and immediate consideration, respectively; $F<1, n s)$. Moreover, flexible participants not only reported less intention to rent in the future than inflexible participants did (5.62 vs. 6.67, respectively), $F(1,104)=6.87, p=.010$, $\eta_{\mathrm{p}}^{2}=.062$, but also reported greater intention to rent immediately than the inflexible participants did (5.54 vs. 4.81, respectively), $F(1,104)=3.10, p=.081, \eta_{p}^{2}=.029$. The latter difference suggests that perspective flexibility led participants to take an allocentric perspective when they considered renting the apartment immediately as well as in the future.

\section{Experiment 2}

\section{Effects of Temporal Orientation and Temporal Distance}

Experiment 1 provided evidence that inducing individuals to consider a situation from several different points of view increased their perspective flexibility, leading them to take an allocentric perspective when construing the implications of psychologically proximal and distal events and to use different criteria when evaluating these events than they otherwise would. If this is so, and if individuals' social and temporal orientations affect their perspective flexibility, these orientations should affect individuals' construal of these events through their mediating impact on flexibility.

Experiments 2 and 3 evaluated this possibility. Experiment 2 examined the effects of individual differences in temporal orientation on participants' construal of events that differ in temporal distance and on the criteria they use to evaluate these events. We varied temporal orientation by a thought-listing task (Kopalle et al., 2010). In Experiment 2a, participants considered renting an intrinsically desirable but unfeasible apartment either immediately or in the future, as in Experiment 1. We expected that the tendency to evaluate apartment more favorably for future occupancy than for immediate occupancy would only be evident when participants had a short-term temporal orientation. Moreover, inducing a longterm orientation should decrease evaluations of the apartment for future rental but should increase evaluations of it for immediate rental. Finally, these effects should be mediated by the effects of temporal orientation on perspective flexibility.

In Experiment 2b, however, participants were presented with a similar scenario involving an apartment with unfavorable high- 
level features but favorable context-specific features. We expected that the effects of temporal orientation and temporal distance in this experiment would be the mirror image of those observed in Experiment 2a.

\section{Experiment 2a}

\section{Method.}

Participants and design. One hundred eighty-six adults (58\% female, $M_{\text {age }}=35.40$ ) were recruited on Amazon Mechanical Turk (MTurk), a research platform validated by Paolacci, Chandler, and Ipeirotis (2010). They were randomly assigned to cells of a 2 (Temporal Orientation: short-term vs. long-term orientation) $\times$ 2 (Temporal Distance: immediate vs. future) between-subjects design.

Procedure. Participants were told they would take part in three unrelated tasks. The first task, described as a test of reading comprehension and writing skills, activated their temporal orientation. In short-term orientation conditions, participants first read a short paragraph regarding the importance of treasuring the here and now without focusing too much on the future:

"Yesterday is History. Tomorrow is a Mystery. Today is a Gift. That's why it's called the Present." Many people get in trouble by focusing too much on the future, without treasuring the opportunities that come from the here and now. On the other hand, many people who make each day count by treasuring the happiness and opportunities that exist in the present have ended up wealthy and happy. Thinking about the immediate future has frequently led to better results for them.

After reading the paragraph, participants described three instances in their lives in which they had taken actions that involved enjoying the here and now without thinking about the consequences for the future, and that proved to be beneficial to their lives.

In long-term orientation conditions, participants read a paragraph that stressed the importance of thinking about the future:

\footnotetext{
"Don't sacrifice your long-term opportunities for a temporary benefit." Many people get in trouble by focusing on immediate benefit without considering the long-term consequences. They often engage in risky behavior (e.g., drug use) without regard to its implications for their future life and well-being. In contrast, many people who have given up immediate pleasure for future profit have ended up both wealthy and happy and more satisfied with their life as a whole.
}

Then, they described three life experiences in which they had taken actions that required making a sacrifice at the time but that proved to be beneficial in the long term. After describing the three events in each condition, participants were asked to pick one of the events they mentioned and to describe it in greater detail.

After completing this task, participants performed a 2-min word puzzle as a filler task. Then, they were given the description of the desirable but nonfeasible apartment employed in Experiment 1 and estimated the likelihood of renting it either "now" or "1 year later" along a scale from 1 (very unlikely) to 9 (very likely).

Participants' perspective flexibility along the temporal dimension was then assessed using two items adopted from McFerran, Dahl, Gorn, and Honea's (2010) measure of mental transportation: "To what extent did you take a future perspective when you made decisions in the previous situation?" and "To what extent did you put yourself at a future point in time when you made the decisions in the previous situation?" Responses reported along a scale from 1 (not at all) to 9 (very much) were averaged $(\alpha=.90)$.

Participants also completed a measure of temporal orientation employed by Bearden, Money, and Nevins (2006), including these items: "I plan for the long term," "I work hard for success in the future," "I don't mind giving up today's fun for success in the future," and "Persistence is important to me." Responses, reported along a scale from 1 (totally disagree) to 9 (totally agree) were averaged $(\alpha=.81)$ to form a temporal orientation index with high scores indicating long-term orientation. Finally, participants also completed a 12-item version of the horizontal individualismcollectivism scale (Singelis et al., 1995), which was composed of six items pertaining to collectivism $(\alpha=.78)$ and another six pertaining to individualism $(\alpha=.72)$. The responses to the two sets of items were combined as an index of social orientation, with higher score indicating collectivism.

\section{Results.}

Manipulation check. Participants reported having a longer temporal orientation in long-term orientation conditions $(M=$ 7.16, $S D=1.51)$ than in short-term orientation conditions $(M=$ $6.66, S D=1.43), F(1,182)=5.29, p=.023, \eta_{\mathrm{p}}^{2}=.028$ However, the manipulation of temporal orientation had no influence on participants' social orientation $(F \mathrm{~s}<1, n s)$, indicating that the two orientations are unrelated and should be distinguished.

Perspective flexibility. Analyses of perspective flexibility revealed a significant main effect of temporal orientation. Participants with a long-term orientation were more disposed to project themselves into the future $(M=6.72, S D=1.76)$ than were those with a short-term orient orientation $(M=5.48, S D=2.08)$, $F(1,182)=18.36, p<.001, \eta_{\mathrm{p}}^{2}=.092$. No other effects were significant $(F \mathrm{~s}<1, n s)$. Thus asking participants to judge an apartment at different levels of temporal distance did not in itself influence their perspective flexibility.

Intention to rent. The top section of Table 2 shows participants' intention to rent the apartment as a function of temporal distance and temporal orientation. Analyses of these data yielded both a significant effect of temporal distance, $F(1,182)=5.21$, $p=.024, \eta_{\mathrm{p}}^{2}=.028$, and an interaction of these variables, $F(1$, $182)=9.05, p=.003, \eta_{\mathrm{p}}^{2}=.047$. When individuals had a short-term temporal orientation, they evaluated the apartment more favorably when they considered it for future occupancy $(M=$

Table 2

Intention to Rent an Apartment as a Function of Temporal Orientation and Temporal Distance: Experiments $2 a$ and $2 b$

\begin{tabular}{|c|c|c|}
\hline \multirow[b]{2}{*}{ Temporal orientation } & \multicolumn{2}{|c|}{ Temporal distance } \\
\hline & Now & 1 Year later \\
\hline \multicolumn{3}{|c|}{$\begin{array}{l}\text { Experiment 2a: Desirable but infeasible } \\
\text { apartment }\end{array}$} \\
\hline Short-term orientation & $3.91^{\mathrm{a}}(1.83)$ & $5.53^{\mathrm{b}}(2.12)$ \\
\hline Long-term orientation & $4.88^{\mathrm{c}}(1.79)$ & $4.66^{\mathrm{b}, \mathrm{c}}(2.36)$ \\
\hline \multicolumn{3}{|l|}{$\begin{array}{l}\text { Experiment 2b: Feasible but } \\
\text { undesirable apartment }\end{array}$} \\
\hline Short-term orientation & $5.40^{\mathrm{a}}(1.62)$ & $4.17^{\mathrm{b}}(2.08)$ \\
\hline Long-term orientation & $4.71^{\mathrm{a}, \mathrm{c}}(1.90)$ & $5.07^{\mathrm{c}}(2.01)$ \\
\hline
\end{tabular}

Note. $\quad N=186$ for Experiment 2a; $N=193$ for Experiment 2b. Standard deviations are given in parentheses. For each experiment, cells with unlike superscripts in each row and column differ at $p \leq .05$. 
5.53) than when they considered it for immediate occupancy $(M=$ 3.91), $F(1,182)=13.21, p<.001, \eta_{\mathrm{p}}^{2}=.065$. However, inducing a long-term orientation decreased participants' intentions to rent the apartment in the future (from 5.53 to 4.66), $F(1,182)=3.79$, $p=.054, \eta_{\mathrm{p}}^{2}=.037$, but increased their intentions to rent it immediately (from 3.91 to 4.88 ), $F(1,182)=5.91, p=.017, \eta_{\mathrm{p}}^{2}=$ .066 .

Mediation analyses. Perspective flexibility was assumed to mediate the influence of temporal orientation on temporal construal. To confirm this assumption, we conducted mediation analysis using the PROCESS macro developed by (Hayes, 2013, Model 15). Based on 5,000 bias corrected bootstrapping resamples, the indirect effect was significant and positive in immediate rental conditions (95\% confidence interval [CI] [.0208, .6103]), but was significant and negative in future rental conditions $(95 \%$ CI $[-.7278,-.0130])$. These results lend support to our predictions.

Effect of assessed social orientation. Regression analyses were performed on intentions to rent as a function of temporal distance, participants' assessment of their social orientation and their interaction. Although the interaction was not significant $(B=-.21, S E=.17), t(182)=1.29, p=.198$, it was directionally consistent with expectations. Spotlight analyses revealed that individualists (participants who were $1 S D$ below the mean in social orientation) judged the apartment more favorably when they considered it for the future than when they considered it immediately $(5.53$ vs. 4.54 , respectively; $B=1.00, S E=.43), t(182)=$ $2.32, p=.022, \eta_{\mathrm{p}}^{2}=.029$, whereas collectivists (participants who were $1 S D$ above the mean in social orientation) did not differ (4.67 vs. 4.46 , respectively; $B=.21, S E=.43, t<1, n s$ ).

\section{Experiment 2b}

In this study, the valences of desirable and feasible apartment descriptions were the reverse of those in Experiment 2a. Thus, we expected that the effects of temporal orientation and temporal distance would be the opposite of those we observed in that experiment.

Method: Participants, design, and procedure. One hundred ninety-three participants were recruited from MTurk website $(53 \%$ female, $\left.M_{\text {age }}=36.64\right)$. The procedure of Experiment $2 \mathrm{~b}$ was identical to that of Experiment 2a, except for the description of the stimuli. Specifically, participants whose short-term versus longterm temporal orientation was primed using a thought-listing task rated on their intention to rent an apartment with favorable situation-specific features (i.e., flexible moving-in date and low moving expense) but unfavorable desirability-related features (i.e., limited living space with furniture not included; see Appendix B for a description of the apartment).

Results. Participants reported higher long-term orientation when this orientation was primed $(M=7.11, S D=1.40)$ than when a short-term orientation was primed $(M=6.53, S D=1.46)$, $F(1,189)=8.04, p=.005, \eta_{\mathrm{p}}^{2}=.041 ; \alpha=.87$, indicating that our manipulation was successful.

Analyses of perspective flexibility $(\alpha=.78)$ revealed only a significant main effect of temporal orientation, $F(1,189)=5.97$, $p=.015, \eta_{\mathrm{p}}^{2}=.031$, indicating that a long-term (vs. short-term) orientation priming increased participants' tendency to consider the situation in a future perspective $(M=6.39, S D=1.71$ vs. $M=$ 5.52, $S D=1.98$ ).

Participants' intentions to rent the apartment are shown in the second section of Table 2 as a function of temporal distance and temporal orientation. Analyses yielded a significant interaction of these variables, $F(1,189)=8.35, p=.004, \eta_{\mathrm{p}}^{2}=.042$. Specifically, participants with a short-term temporal orientation evaluated the apartment more favorably when they considered it for immediate occupancy than when they considered it for future occupancy $\left(5.40\right.$ vs. 4.17 , respectively), $F(1,189)=9.12, p=.003, \eta_{\mathrm{p}}^{2}=$ .046. However, inducing a long-term orientation increased participants' intention to rent the apartment in the future (from 4.17 to 5.07), $F(1,189)=5.20, p=.024, \eta_{\mathrm{p}}^{2}=.027$, but decreased their intention to rent it immediately (from 5.40 to 4.71 ), $F(1,189)=$ $3.24, p=.073, \eta_{\mathrm{p}}^{2}=.017$. These results are the mirror images of those observed in Experiment 2a.

Finally, we used bootstrap procedures to test the mediating role of perspective flexibility using the PROCESS macro (Model 15). This analysis revealed that the indirect effect was significant and negative in immediate rental conditions (based on 5,000 samples, 95\% CI $[-.3694,-.0230])$, but was significant and positive in future rental conditions (95\% CI [.0197, .4667]).

\section{Discussion}

When individuals had a short-term temporal orientation, the effect of temporal distance in the relative emphasis they placed on high-level versus situation-specific features of the apartment was consistent with implications of construal level theory. However, inducing a long-term orientation led individuals to take an allocentric perspective when construing the information they received. As a result, they decreased their emphasis on high-level features and increased their emphasis on situation-specific features when they considered the apartment for the future, but increased their emphasis on high-level features and decreased their emphasis on situation-specific features when they considered it for immediate rental.

The results call into question an alternative conceptualization of the effect of temporal orientation. That is, a long-term temporal orientation might lead to selective attention to features that are particularly relevant to the future (i.e., high-level features). If this were the case, however, the effect of temporal orientation on evaluations of the apartment would be independent of temporal distance. This was clearly not the case. Thus, our results are more consistent with our assumption that temporal orientation determines the process that people employ in construing the implications of information and not simply the content of the information they consider.

\section{Experiment 3}

\section{Effects of Social Orientation and Social Distance}

Experiment 2 confirmed our prediction that inducing a longterm temporal orientation influenced the construal level of temporally constrained events, and this effect was driven by the flexibility of the perspective they took in construing the implications of the events they considered. Experiments $3 \mathrm{a}$ and $3 \mathrm{~b}$ evaluated the interactive effects of social orientation and social distance on 
construal level and provided further empirical evidence of the mediating role of perspective flexibility. In these studies, participants whose individualistic or collectivistic orientation was primed considered an apartment identical to that employed in previous studies (in Experiment 3a, an intrinsically desirable but unfeasible apartment; in Experiment 3b, a feasible but undesirable apartment), and either indicated their own intention to rent the apartment or predicted another person's intention to do so. We expected that an individualistic orientation would lead the effect of social distance on judgments to be similar to that implied by construal level theory, but that the induction of a collectivistic orientation would decrease this effect.

\section{Experiment 3a}

\section{Method.}

Participants and design. One hundred forty-eight Hong Kong undergraduate students participated in the study for HK\$40 (about US\$5). They were randomly assigned to conditions of a 2 (Social Orientation: individualism vs. collectivism) $\times 2$ (Social Distance: self vs. a stranger) between-subjects design.

Procedure. First, participants' social orientation was manipulated using the procedure employed by Gardner, Gabriel, and Lee (1999). Specifically, participants read a 200-word article. In individualism conditions, they were asked to circle first-person singular pronouns (I, me, mine, etc.) and in collectivism conditions, they were asked to circle first-person plural pronouns (we, us, our, etc.). Then, after a filler task, participants were exposed to the apartment-judgment task similar to the one used in Experiment 2a. In self-rating conditions, they decided whether to move into the apartment themselves, and in stranger-rating conditions, they predicted the likelihood that another Hong Kong resident they did not know would rent the apartment. Responses were made along a scale from 1 (very unlikely) to 9 (very likely).

Participants' general perspective flexibility was assessed using the scale employed in Experiment $1(\alpha=.71)$. Finally, participants completed the temporal orientation scale $(\alpha=.75)$ used in Experiment 1 and the scale of individualism and collectivism used in Experiment 2 (for individualism, $\alpha=.76$; for collectivism, $\alpha=$ .70).

\section{Results.}

Manipulation check. Social orientation was manipulated successfully. Participants reported higher collectivism if they circled first-person plural pronouns $(M=9.91, S D=1.24)$ than if they circled first-person singular pronouns $(M=9.39, S D=1.75), F(1$, $144)=3.52, p=.063, \eta_{\mathrm{p}}^{2}=.024$. However, the manipulation of social orientation did not influence temporal orientation $(F<1$, $n s)$. This confirms the conclusion that temporal and social orientations are independent.

Perspective flexibility. Collectivists were more disposed to take a flexible perspective when processing information $(M=$ $7.02, S D=1.19)$ than individualists were $(M=6.47, S D=1.20)$, $F(1,144)=7.64, p=.006, \eta_{\mathrm{p}}^{2}=.050$. No other effects were significant $(F<1, n s)$.

Intention to rent. Participants' apartment evaluations are summarized in the first section of Table 3 as a function of social orientation and social distance. The interaction of these variables was significant, $F(1,144)=10.13, p=.002, \eta_{\mathrm{p}}^{2}=.066$, and of the form expected. Participants with an individualistic orientation
Table 3

Intention to Rent an Apartment as a Function of Social Orientation and Social Distance: Experiments $3 a$ and $3 b$

\begin{tabular}{llr}
\hline & \multicolumn{2}{c}{ Social distance } \\
\cline { 2 - 3 } Social orientation & \multicolumn{1}{c}{ Self } & \multicolumn{1}{c}{ Another } \\
\hline $\begin{array}{l}\text { Experiment 3a: Desirable but } \\
\quad \text { infeasible apartment }\end{array}$ & & \\
$\quad$ Individualism & $5.03^{\mathrm{a}}(1.74)$ & $6.21^{\mathrm{b}}(1.14)$ \\
$\quad$ Collectivism & $5.73^{\mathrm{c}}(1.65)$ & $5.30^{\mathrm{c}}(1.57)$ \\
$\begin{array}{l}\text { Experiment 3b: Feasible but } \\
\text { undesirable apartment }\end{array}$ & & \\
$\quad$ Individualism & $5.48^{\mathrm{a}}(1.53)$ & $4.10^{\mathrm{b}}(2.05)$ \\
Collectivism & $4.40^{\mathrm{c}}(1.69)$ & $5.04^{\mathrm{b}, \mathrm{c}}(1.75)$ \\
\hline
\end{tabular}

Note. $\quad N=148$ for Experiment 3a; $N=92$ for Experiment 3b. Standard deviations are given in parentheses. For each experiment, cells with unlike superscripts in each row and column differ at $p \leq .05$.

evaluated the apartment more favorably when they considered another person renting it $(M=6.21)$ than when they considered renting it themselves $(M=5.03), F(1,144)=11.14, p=.001$, $\eta_{\mathrm{p}}^{2}=.072$. However, inducing a collectivistic orientation decreased their evaluations of the apartment (from 6.21 to 5.30) when they thought about another person renting it, $F(1,144)=$ $6.60, p=.011, \eta_{\mathrm{p}}^{2}=.044$, but increased their evaluations of it when they considered renting it themselves (from 5.03 to 5.73), $F(1,144)=3.75, p=.050, \eta_{\mathrm{p}}^{2}=.025$.

Mediation analyses. Mediation analyses (Process Model 15) confirmed the mediating effect of perspective flexibility in a mediated moderation model. Bootstrapping based on 5,000 bias corrected resamples confirmed that the effect of social orientation on construal level was positively mediated by perspective flexibility when participants made decisions for themselves $(95 \% \mathrm{CI}$ $[.0011, .5589])$ but was negatively mediated by perspective flexibility when they predicted another's intentions (95\% CI $[-.4460,-.0369])$.

Effect of assessed temporal orientation. A regression analysis was performed on intention to rent as a function of temporal orientation, social distance, and their interaction. The interaction was significant $(B=-.42, S E=.17), t(144)=2.42, p=.017$, and of the form expected. Spotlight analysis showed that participants with a short-term temporal orientation (1 SD below the mean) evaluated the apartment more favorably when considering it for a stranger than when they considered it for themselves (6.12 vs. 5.09 , respectively; $B=1.04, S E=.36), t(144)=2.89, p=.005$, $\eta_{\mathrm{p}}^{2}=.054$, but not for those with a long-term orientation (5.71 vs. 5.49; $B=-.24, S E=.36, t<1, n s)$.

\section{Experiment 3b}

Method: Participants, design, and procedure. Ninety-two undergraduates from Hong Kong participated in this study. Each participant received HK\$40 (about US\$5) for participating in a 0.5 -hr study session. The procedure of this experiment replicated that of Experiment $3 \mathrm{a}$, except that we used an apartment with favorable situation-specific features but unfavorable desirabilityrelated features (identical to Experiment 2 b) to replace the desirable but infeasible apartment description. 
Results. The manipulation of social orientation was successful. Participants who circled first-person plural pronouns scored higher on the social orientation index than those who circled first-person singular pronouns $(M=9.95, S D=.96$ vs. $M=9.34$, $S D=.97), F(1,87)=8.89, p=.004, \eta_{\mathrm{p}}^{2}=.093$ (for individualism, $\alpha=.73$; for collectivism, $\alpha=.68$ ). The manipulation of social orientation did not influence assessed temporal orientation, $F(1,87)=1.09, p=.299$.

The bottom half of Table 3 summarizes participants' intention to rent the apartment as a function of social orientation and social distance. Consistent with our prediction, the two-way interaction was significant, $F(1,87)=7.53, p=.007, \eta_{\mathrm{p}}^{2}=.079$. When they considered occupancy for themselves, collectivists were less willing to rent the apartment than individualists were (4.40 vs. 5.48, respectively), $F(1,87)=4.20, p=.044, \eta_{\mathrm{p}}^{2}=.046$. When they considered a stranger's occupancy of the apartment, however, the reverse was true (5.04 vs. 4.10 , respectively), $F(1,87)=3.35, p=$ $.071, \eta_{\mathrm{p}}^{2}=.037$. Put another way, although individualists rated the stranger's intention to rent the apartment to be lower than their own (4.10 vs. 5.48), $F(1,87)=7.09, p=.009 \eta_{\mathrm{p}}^{2}=.075$, collectivists' ratings did not significantly differ in the two conditions (5.04 vs. 4.40$), F(1,87)=1.49, p=.225$.

Moreover, collectivists reported a more flexible perspective than individualists $(M=6.47, S D=.93$ vs. $M=5.43, S D=.94)$, $F(1,87)=29.33, p<.001, \eta_{\mathrm{p}}^{2}=.252(\alpha=.70)$. Bootstrapping analyses using the PROCESS macro (Model 15) indicated that the indirect effect of social orientation on intention to rent was negatively mediated by perspective flexibility when participants considered the occupancy for themselves (based on 5,000 samples, $90 \%$ CI $[-.8597,-.0324])$ but was positively mediated by perspective flexibility when they predicted a stranger's intentions (90\% CI [.8847, 2.1702]).

\section{Discussion}

Experiment 3 provided evidence that collectivists are more likely than individualists to shift their perspective when processing information about themselves and another person. Thus, although the effect of social distance on individualists' weighting of highlevel and low-level features were consistent with implications of construal level theory, collectivists appeared to give the same weight to both types of features regardless of social distance. This difference was mediated by the effects of participants' social orientation on their perspective flexibility.

\section{Experiment 4}

\section{Effects of Temporal Orientation and Social Distance}

The effects of temporal and social orientation on construal level that we observed in Experiments 2 and 3 were specific to the dimension to which this orientation directly pertained. If the effects are mediated by perspective flexibility, however, they should also be evident along dimensions to which temporal or social orientation is not directly related. Experiments 4 and 5 tested this expectation.

\section{Method}

One hundred thirteen Hong Kong undergraduates participated in the experiment. They were assigned randomly to cells of a 2
(Temporal Orientation: short-term vs. long-term orientation) $\times 2$ (Social Distance: self vs. a stranger) between-subjects design. Participants' temporal orientation was manipulated in the manner employed in Experiments 2a and 2b. That is, participants were asked to recall three beneficial experiences that concerned either planning for the future (in long-term orientation conditions) or enjoying the here and now (in short-term orientation conditions). After completing both this task and a filler task, participants were given the description of a hotel with a superior reputation (a global criterion for evaluation) but small rooms (i.e., a concrete concern). The favorableness of both attributes was described using stars (i.e., ${ }^{* * * *}=$ unfavorable, ${ }^{* * * * * *}=$ favorable). (An independent pretest with 28 participants from the same participant pool indicated that the two attributes were equally important.) To vary social distance, participants were told to imagine that either they or another Hong Kong resident were considering staying in the hotel. Participants estimated the likelihood of staying in the hotel along a scale from 1 (very unlikely) to 9 (very likely). (Thus, a higher intention to stay indicated a higher level of construal of the event.) Finally, they completed the temporal orientation scale $(\alpha=.77)$ and the social orientation scale (for individualism, $\alpha=.69$; for collectivism, $\alpha=$ .70) used in previous studies.

\section{Results}

Manipulation check. Long-term oriented participants scored higher $(M=6.38, S D=1.35)$ than short-term oriented participants on the temporal orientation index $(M=5.26, S D=1.67)$, $F(1,109)=15.30, p<.001, \eta_{\mathrm{p}}^{2}=.123$. However, the manipulation of temporal orientation did not influence social orientation $(F<1, n s)$.

Hotel evaluations. We expected that participants with a longterm orientation would predict that a stranger was less likely to stay at the hotel, but would report a greater likelihood of staying there themselves, than would participants with a short-term orientation. The results summarized in Table 4 confirmed these expectations. Although the main effect of social distance was significant, $F(1,109)=11.04, p=.001, \eta_{\mathrm{p}}^{2}=.092$, it was qualified by an interaction of social distance and temporal orientation, $F(1,109)=$ 7.32, $p=.008, \eta_{\mathrm{p}}^{2}=.063$. Participants with a short-term temporal orientation reported that another person was more likely to take a desirable but infeasible hotel room $(M=6.10)$ than they were themselves $(M=4.24), F(1,109)=18.36, p<.001, \eta_{\mathrm{p}}^{2}=.144$. However, inducing a long-term perspective decreased participants' estimates of the likelihood that another person would take the room (from 6.10 to 5.32), $F(1,109)=3.12, p=.080, \eta_{\mathrm{p}}^{2}=.028$,

Table 4

Intention to Stay in a Hotel With a Superior Brand but Small

Rooms as a Function of Temporal Orientation and Social Distance: Experiment 4

\begin{tabular}{llr}
\hline & \multicolumn{2}{c}{ Social distance } \\
\cline { 2 - 3 } Temporal orientation & \multicolumn{1}{c}{ Self } & \multicolumn{1}{c}{ Another } \\
\hline Short-term orientation & $4.24^{\mathrm{a}}(1.51)$ & $6.10^{\mathrm{b}}(1.80)$ \\
Long-term orientation & $5.13^{\mathrm{c}}(1.78)$ & $5.32^{\mathrm{b}, \mathrm{c}}(1.35)$ \\
\hline
\end{tabular}

Note. $\quad N=113$. Standard deviations are given in parentheses. Cells with unlike superscripts in each row and column differ at $p \leq .05$. 
but increased their own likelihood of doing so (from 4.24 to 5.13), $F(1,109)=4.26, p=.041, \eta_{\mathrm{p}}^{2}=.038$.

\section{Discussion}

Experiment 4 provided evidence that temporal orientation influences the abstractness of construals along a social dimension as well as a temporal dimension. Although the effect of temporal orientation on perspective flexibility was not assessed in this experiment, the effect observed in Experiment 2 provides confidence in this effect. To this extent, our findings are consistent with our assumption that the effects of temporal orientation are mediated by perspective flexibility and thus a disposition to take an allocentric perspective regardless of the dimension of psychological distance involved.

Although an interpretation of our findings in terms of construal level theory is possible, several ad hoc assumptions may be necessary to do so. That is, one would have to assume that the level of abstractness of construals along one dimension of psychological distance generalizes to other dimensions. However, temporal distance was neither manipulated nor assessed in this study and the induction of temporal orientation was not obviously related to the dependent variable task. Moreover, this interpretation would not in itself explain why temporal orientation affects construals along a temporal dimension in the first place. Thus, an interpretation in terms of perspective flexibility seems more viable.

\section{Experiment 5}

\section{Effects of Social Orientation and Temporal Distance}

Experiment 5 provided further confirmation of the hypothesis that the effect of social orientation, like the effect of temporal orientation, generalized to judgments along dimensions to which the orientation is not directly related. This was done using a different manipulation of social orientation than we employed in Experiment 3.

\section{Method}

One hundred twenty-six bilingual Hong Kong undergraduate students were randomly assigned to cells of a 2 (Social Orientation: individualism vs. collectivism) $\times 2$ (Temporal Distance: immediate vs. future) between-subjects design.

Social orientation was manipulated using a procedure employed by Trafimow, Triandis, and Goto (1991). Specifically, participants in individualism conditions were asked to spend five minutes thinking and writing about "What makes you different from your family and friends?" Participants in collectivism conditions thought and wrote about "What do you have in common with your family and friends?" Then, after a filler task, participants estimated the likelihood of renting a hotel room either now or 1 year later, based on descriptions identical to those employed in Experiment 3 (i.e., with positive high-level features but negative low-level features) along scales from 1 (very unlikely/not probable) to 9 (very likely/very probable; $\alpha=.96$ ). (Thus, a greater intention to rent the hotel room indicated a greater emphasis on high-level features.) Finally, participants completed the temporal orientation scale $(\alpha=$
.87) and the social orientation scale used in other studies (for individualism, $\alpha=.70$; for collectivism, $\alpha=.71$ ).

\section{Results and Discussion}

Manipulation check. The manipulation of social orientation was successful. Collectivists scored higher $(M=10.63, S D=$ 1.21) than individualists on the social orientation index $(M=9.97$, $S D=1.14), F(1,122)=9.74, p=.002, \eta_{\mathrm{p}}^{2}=.074$. No other effects were significant $(F \mathrm{~s}<1, n s)$. Moreover, the manipulation of social orientation did not influence temporal orientation $(F<1$, $n s)$.

Hotel evaluations. Participants' intentions to visit the hotel are summarized in Table 5. The predicted interaction of social orientation and temporal distance was significant, $F(1,122)=$ 14.93, $p<.001, \eta_{\mathrm{p}}^{2}=.109$, along with a main effect of temporal distance, $F(1,122)=11.81, p=.001 \eta_{\mathrm{p}}^{2}=.088$. When individualism was primed, participants evaluated the hotel more favorably when they considered it for future occupancy $(M=6.47)$ than when they considered it for immediate occupancy $(M=4.60)$, $F(1,122)=26.64, p<.001, \eta_{\mathrm{p}}^{2}=.179$. However, inducing a collectivistic orientation decreased evaluations of the hotel (from 6.47 to 5.23) when they considered it for future occupancy, $F(1$, $122)=12.67, p=.001, \eta_{\mathrm{p}}^{2}=.094$, but increased evaluations of the hotel (from 4.60 to 5.34) when they considered taking a room immediately, $F(1,122)=3.89, p=.052, \eta_{\mathrm{p}}^{2}=.031$.

Thus, the results of Experiment 5 confirmed the conclusions drawn from Experiment 4. In combination, Experiments 4 and 5 showed that both social orientation and temporal orientation can influence the flexibility of perspective taking along dimensions to which they do not directly pertain.

\section{Experiment 6}

\section{Cultural Differences in Perspective Flexibility}

In previous experiments, social and temporal orientations were situationally induced. Chronic cultural differences in these orientations, however, may also exist (Hofstede, 1991; Triandis, 1995). To this extent, cultural differences in the effects of temporal and social distances on the interpretation of events should parallel the effects of manipulated differences. Experiment 6 evaluated this possibility.

Moreover, the previous studies employed a single experimental task that assessed the tradeoff between high level and contextspecific features of stimuli. To increase confidence in the gener-

Table 5

Intention to Stay in a Hotel With a Superior Brand but Small Rooms as a Function of Social Orientation and Temporal Distance: Experiment 5

\begin{tabular}{lcc}
\hline \multirow{2}{*}{ Social orientation } & \multicolumn{2}{c}{ Temporal distance } \\
\cline { 2 - 3 } & \multicolumn{1}{c}{ Now } & 1 Year later \\
\hline Individualism & $4.60^{\mathrm{a}}(1.42)$ & $6.47^{\mathrm{b}}(1.44)$ \\
Collectivism & $5.34^{\mathrm{a}, \mathrm{c}}(1.33)$ & $5.23^{\mathrm{c}}(1.51)$ \\
\hline
\end{tabular}

Note. $\quad N=126$. Standard deviations are given in parentheses. Cells with unlike superscripts in each row and column differ at $p \leq .05$. 
ality of our conclusions, we used a different operationalization of construal level in a categorization task in Experiment 6 (Liberman, Sagristano, \& Trope, 2002). Because abstract categories are more inclusive, people who construe information at a high (vs. low) level tend to classify objective using fewer categories.

\section{Method}

One hundred two participants from United States (49\% female, $\left.M_{\text {age }}=35.93\right)$ and 95 Indian participants $\left(46 \%\right.$ female, $M_{\text {age }}=$ 33.66) were recruited on Amazon MTurk (for a discussion of conducting cross-cultural comparison on MTurk, see Paolacci et al., 2010; Seih, Buhrmester, Lin, Huang, \& Swann, 2013; Slabu, Lenton, Sedikides, \& Bruder, 2014). For U.S. participants, those with an Asian background (e.g., Chinese, Indians) were not included in analysis.

Participants performed a task that was ostensibly to determine how people plan for activities. Specifically, participants read a scenario in which they imagined going on a trip and were asked to categorize a list of 33 items they would bring on the trip into as many groups as they like without overlapping. Half of the participants were told that the trip will take place tomorrow whereas the other half were informed that the trip is scheduled for 1 year later. All participants then completed the measures of perspective flexibility $(\alpha=.85)$, temporal orientation $(\alpha=.76)$ and social orientation $(\alpha s>.87)$ used in earlier experiments.

\section{Results}

Temporal orientation, social orientation, and perspective flexibility. Consistent with expectations, Indians scored higher than North Americans in both temporal orientation $(M=7.47$, $S D=1.22$ vs. $M=6.91, S D=1.83$, respectively), $F(1,193)=$ $5.80, p=.017, \eta_{\mathrm{p}}^{2}=.029$, and social orientation $(M=9.95, S D=$ 1.07 vs. $M=8.67, S D=2.20$, respectively), $F(1,193)=25.63$, $p<.001, \eta_{\mathrm{p}}^{2}=.117$. Moreover, they reported significantly higher perspective flexibility than North Americans did $(M=7.23, S D=$ 1.08 vs. $M=6.80, S D=1.43), F(1,193)=5.38, p=.021, \eta_{\mathrm{p}}^{2}=$ .027 .

Number of categories. Analyses of the number of categories that participants used to classify the objects yielded a significant main effect of temporal distance, $F(1,193)=14.02, p<.001$, $\eta_{\mathrm{p}}^{2}=.068$, which was further qualified by its interactive effect with culture, $F(1,193)=5.16, p=.024, \eta_{\mathrm{p}}^{2}=.026$. As predicted, although North American participants created fewer categories for a temporally distal trip than for an immediate trip, $M=3.47, S D=1.44$ vs. $M=4.94, S D=1.50), F(1,193)=18.95, p<.001, \eta_{\mathrm{p}}^{2}=.089$, this pattern was nonsignificant for Indian participants $(M=3.98$, $S D=2.08$ vs. $M=4.34, S D=1.68$, respectively), $F(1,193)=1.04$, $p=.310, \eta_{\mathrm{p}}^{2}=.005$. Moreover, Indians created fewer categories for an immediate trip than North Americans did (4.34 vs. 4.94), $F(1$, $193)=2.81, p=.095, \eta_{\mathrm{p}}^{2}=.014$, but created more categories than North Americans did for a trip 1 year later (3.98 vs. 3.47), $F(1,193)=$ 2.35, $p=.127, \eta_{\mathrm{p}}^{2}=.012$.

Mediation analyses. Bootstrapping analyses based on 5,000 resamples (Process Model 15) indicated that the indirect effect of culture on number of categories was negatively mediated by perspective flexibility for an immediate trip (90\% CI $[-.3467,-.0141])$ but was positively mediated by perspective flexibility for a temporally distal trip (90\% CI [.0031, .3007]).

\section{Discussion}

Experiment 6 directly compared members from different cultures on their construal level of temporally constrained events. Indian participants generated fewer categories of items than North Americans for a trip taking place immediately but created more categories than the latter for a trip 1 year later. Thus, Indians thought more concretely than North Americans when considering events in the distant future but thought more abstractly than North Americans when considering immediate events. In summary, chronic differences in social and temporal orientation influence participants' construals of events in the same way that situationally induced orientations influence these construals.

\section{Experiment 7}

\section{Effect of Perspective Flexibility on Task Initiation}

The preceding studies provide strong evidence that perspective flexibility can lead individuals to take an allocentric perspective when they construe the implications of socially and temporally constrained events. However, a basic assumption of our conceptualization was not directly examined. According to our conceptualization, all individuals spontaneously construe information from an egocentric perspective when they first interpret it. However, collectivists, or individuals with a long-term temporal orientation, shift their perspective to an allocentric point of view at the time of judgment. An alternative possibility, however, is that these individuals take an allocentric perspective spontaneously and that a shift in perspective is not involved. To distinguish between these alternative possibilities, we capitalized on previous evidence that shifting to an allocentric perspective requires cognitive resources (Davis et al., 1996; Galinsky \& Moskowitz, 2000). If this is so, putting individuals under a cognitive load while they make a decision about starting the task should decrease the likelihood of shifting perspective and lead them to take an egocentric perspective by default, regardless of whether a collectivistic orientation has been primed.

We investigated this possibility using a different research paradigm from that employed in earlier studies. Participants who were primed to have an individualistic or collectivistic orientation were asked to report the time they would begin work on a task for which a future time deadline was imposed. We assumed that participants would be motivated to begin work sooner if they perceived the deadline to be imminent than if they perceived it to be in the more distant future. Thus, suppose both individualists and collectivists spontaneously take an egocentric perspective when they first interpret the information but that collectivists then shift to an allocentric perspective when making their decisions. To this extent, collectivists should perceive the deadline to be closer, and should begin work sooner, than individualists do.

However, suppose participants are under cognitive load. Individualists, who maintain an egocentric perspective, should not be affected. In contrast, collectivists should be prevented from expending the cognitive resources required to shift to an allocentric point of view and consequently should make judgments similar to those that individualists make. If, on the other hand, collectivists take an allocentric perspective directly without shifting their perspective, cognitive load should have little effect on their judgments. 


\section{Method}

One hundred twenty-six Hong Kong undergraduates $\left(M_{\text {age }}=\right.$ 20.81) were randomly assigned to cells of a 2 (Social Orientation: individualism vs. collectivism) $\times 2$ (Cognitive Load: high vs. low) between-subjects design. Participants' social orientation was induced using the procedure employed in Experiment 5 (Trafimow et al., 1991). They were then informed that the experiment was concerned with people's ability to do multiple tasks at the same time and, on this pretense, were asked to hold either a nine-digit number (high cognitive load) or a two-digit number (low cognitive load) in memory as they performed the later tasks. The participants were asked to recall the number at the end of the experiment (for previous uses of this procedure, see Gilbert \& Osborne, 1989; Gilbert, Pelham, \& Krull, 1988).

Participants then read two hypothetical scenarios. In one scenario, participants were asked to "Imagine that you will have a job interview scheduled one month later, and need to make detailed preparation for the interview." In a second scenario, they were asked to "Imagine that you have a term project to complete for a course, and that you have to complete the writing and submit the project two months from now." In each case, they were asked "When are you likely to start working on the task?" and responded along a scale from 1 (definitely soon) to 9 (definitely later). Participants also answered two questions concerning the perspectives they took when contemplating their decision: "To what extent did you think about how you felt now about doing the tasks in the future?" and "To what extent did you think about how you would feel about doing the task at the time it was due?" Responses to these two items, along scales from 1 (not at all) to 9 (very much), were assumed to reflect taking an egocentric and allocentric perspective, respectively.

Participants then completed both the temporal orientation scale $(\alpha=.81)$ and the social orientation scale used in other studies (for individualism, $\alpha=.68$; for collectivism, $\alpha=.72$ ) and indicated the level of difficulty, amount of effort, and amount of thought required to memorize the digit number along three 9-point scales, with a higher score indicating greater load $(\alpha=.87)$.

\section{Results and Discussion}

As Gilbert and Hixon (1991) suggested, a cutoff point was established such that participants who incorrectly reported four or more of the digits were excluded from the data set. Data from six participants were excluded from all analyses.

Manipulation check. Participants reported a greater collectivistic social orientation when collectivism was primed $(M=$ $10.52, S D=.92)$ than when individualism was primed $(M=9.94$, $S D=1.18), F(1,116)=6.07, p=.015, \eta_{\mathrm{p}}^{2}=.050$. As in other studies, however, their temporal orientation was not affected by priming a social orientation $(F<1, n s)$. Participants reported being under greater cognitive load when they had kept a nine-digit number in mind $(M=5.30, S D=1.39)$ than when they had kept a two-digit number in mind $(M=2.26, S D=1.18), F(1,116)=$ $164.06, p<.001, \eta_{\mathrm{p}}^{2}=.586$. No other effects were reliable $\left(F_{\mathrm{s}}<\right.$ $1, n s)$.

Perspective judgments. Analyses of participants' reports of taking an egocentric perspective yielded no main effects of either cognitive load $(F<1, n s)$ or social orientation, $F(1,116)=2.47$, $p=.119$, supporting the notion that all persons take an egocentric perspective by default at the time they first receive and interpret the information, as construal level theory would suggest. However, although participants were less disposed to take an allocentric perspective when they were under cognitive load $(M=6.08, S D=$ 1.61) than when they were not $(M=5.33, S D=2.11), F(1$, 116) $=5.03, p=.027, \eta_{\mathrm{p}}^{2}=042$, this was true only among collectivists. That is, cognitive load significantly decreased collectivists' disposition to take an allocentric perspective (from $M=$ $6.50, S D=1.53$ to $M=5.11, S D=2.06), F(1,116)=8.09, p=$ $\left..005, \eta_{\mathrm{p}}^{2}=.065\right)$, but had no effect on individualists' disposition $(M=5.67, S D=1.61$ vs. $M=5.53, S D=2.17$, respectively, $F<$ $1, n s)$. The interaction of social orientation and cognitive load was marginally significant, $F(1,116)=3.41, p=.067, \eta_{\mathrm{p}}^{2}=.029$.

Task initiation. If collectivists shift their perspective when they are contemplate events that vary in psychological distance, they should evaluate the situations they were asked to consider as temporally closer and thus be inclined to prepare for them sooner than individualists do. However, if cognitive load decreases their disposition to shift perspectives, this difference should not be apparent.

Participants' report of the time they would begin preparing for a job interview that was scheduled for one month later is summarized in the first section of Table 6. Analyses of these data indicated that collectivists reported being likely to initiate the task sooner $(M=4.34, S D=2.01)$ than individualists did $(M=5.13$, $S D=1.91), F(1,116)=4.85, p=.031, \eta_{\mathrm{p}}^{2}=.040$. However, the interaction of social orientation and cognitive load was significant, $F(1,116)=3.94, p=.050, \eta_{\mathrm{p}}^{2}=.033$, and indicated that the aforementioned difference was only evident in low-load conditions (3.83 vs. 5.30, respectively), $F(1,116)=8.78, p=.004, \eta_{\mathrm{p}}^{2}=$ .070 , than in high-load conditions (4.89 vs. $4.97, F<1, n s$ ).

The effects of cognitive load and social orientation on intention to start working on the term project, shown in the second section of the table, were similar. The interaction of these variables was significant, $F(1,116)=3.83, p=.052, \eta_{\mathrm{p}}^{2}=.032$, and indicated that collectivists reported greater intention to start working soon than individualists did when cognitive load was low (4.90 vs. 6.07 , respectively), $F(1,116)=5.03, p=.027, \eta_{\mathrm{p}}^{2}=.042$, but not when the load was high (6.21 vs. $5.94 ; F<1, n s)$.

In summary, the results of Experiment 7 distinguished between two hypotheses concerning the effect of social orientation and its

Table 6

Intention to Initiate a Task With a Future Deadline as a Function of Cognitive Load and Social Orientation: Experiment 7

\begin{tabular}{llc}
\hline & \multicolumn{2}{c}{ Cognitive load } \\
\cline { 2 - 3 } Social orientation & Low & High \\
\hline Job interview & & \\
$\quad$ Individualism & $5.30^{\mathrm{a}}(1.88)$ & $4.97^{\mathrm{a}}(1.96)$ \\
Collectivism & $3.83^{\mathrm{b}}(1.82)$ & $4.89^{\mathrm{a}}(2.01)$ \\
Term project & & \\
$\quad$ Individualism & $6.07^{\mathrm{a}}(2.02)$ & $5.94^{\mathrm{a}}(2.12)$ \\
Collectivism & $4.90^{\mathrm{b}}(1.85)$ & $6.21^{\mathrm{a}}(2.06)$ \\
\hline
\end{tabular}

Note. $\quad N=120$. Standard deviations are given in parentheses. In each scenario, cells with unlike superscripts in each row and column differ at $p \leq .05$. 
impact on perspective flexibility. That is, if individualists and collectivists differ in the perspective they take spontaneously, this difference should be evident regardless of cognitive load. In fact, however, inducing cognitive load eliminated the difference that otherwise existed. Thus, the results are more consistent with the assumption that both collectivists and individualists spontaneously take an egocentric perspective but that collectivists then shift their perspective whereas individualists do not.

\section{General Discussion}

The disposition to construe events in more abstract, high-level terms when the events are psychologically distal than when they are proximal is very well established in applications of construal level theory (Trope \& Liberman, 2010). The assumption that this effect generalizes over dimensions of psychological distance has also been confirmed (Bar-Anan et al., 2006; Yan, 2014). The present research qualifies these effects, however, and, in doing so, provides new insight into the processes that underlie them.

Previous research has implicitly assumed that people typically interpret social events from the perspective of themselves and the here and now and estimate the psychological distance of the events from this egocentric point of view. As our research shows, however, this assumption has limited generality. Seven studies converge on the conclusion that situational and chronic differences exist in the perspective they take when construing social events at different levels of psychological distance. All individuals spontaneously take an egocentric perspective when they first encounter the description of an event, as construal level theory would assume. However, individuals with little perspective flexibility maintain this perspective when they construe the event's implications whereas more flexible persons shift to an allocentric perspective when making these construals. Consequently, they view distant events as closer, but proximal events as further away, than less flexible individuals do.

Perspective flexibility can be induced experimentally, as shown in Experiment 1. However, it is also a byproduct of both chronic and situational differences in social and temporal orientation. People with a collectivistic orientation may acquire a general tendency to shift perspectives as a result of their disposition to see themselves as part of a group and to think of themselves in relation to others. Individuals with a long-term temporal orientation may acquire flexibility as a result of a more general disposition to think about the implications of their present behavior with reference to the future. These different orientations can have different antecedents and, consequently, are uncorrelated. Nevertheless, they both dispose persons to adopt an allocentric perspective when construing social events rather than retaining an egocentric point of view. Therefore, collectivists or persons with a long-term temporal orientation perceive future events or events that involve strangers as less distant, but also perceive immediate events and events that involve themselves as more distant, than do persons who are either individualists or have a short-term temporal orientation.

Our findings converge on these conclusions. Experiment 1 showed that experimentally inducing perspective flexibility decreased the abstractness of participants' construal of future events (suggesting a greater tendency to consider low-level features) but increased the abstractness of their construal of immediate events. Later studies showed that inducing a temporal orientation had similar effects on the construal of events that varied in social distance (Experiment 4) or well as temporal distance (Experiment 2). Correspondingly, inducing a social orientation affected the construal of events that varied in temporal distance (Experiment 5) as well as social distance (Experiment 3). The effects of social and temporal orientation on judgments along a dimension to which these orientations did not directly pertain occurred despite the fact that temporal and social orientations were uncorrelated. Rather, the effects were mediated by the influence of these different orientations on perspective flexibility, as shown in Figure 1. Experiment 6 identified cultural differences in perspective flexibility and showed that the effects of these chronic differences on the construal of temporally distal events are similar to those of situationally activated differences. Finally, Experiment 7 confirmed our assumption that the effect of perspective flexibility can be decreased by factors that prevent individuals from expending the cognitive resources required to engage in this shift.

Our results do not invalidate the general assumption of construal level theory that individuals interpret events in terms of more general, high-level constructs when they perceive the events to be psychologically distant. However, they qualify the assumption that individuals' perception of psychological distance is inherently egocentric. This may be true at the initial comprehension stage of information processing (Wyer \& Radvansky, 1999; Wyer, 2003). When people are called upon to construe the implications of an event for a judgment, however, individuals are often likely to shift their perspective. In these conditions, the implications of construal level theory for the judgments they make may not hold.

Several alternative interpretations of the effect of perspective flexibility are worth noting. First, if individuals are asked to construe a social event at a remote time and place, flexible individuals might spontaneously take the perspective of a person at this time and place. If this were so, however, they should judge distal events more concretely than proximal ones. In fact, however, they judged proximal and distal events similarly. This suggests that although flexible individuals took an allocentric perspective, this perspective was less extreme than that of the distal event they were judging.

A second possibility is that individuals do not shift their perspective to an allocentric point of view but take this perspective spontaneously. The results of Experiment 7, however, showed that inducing cognitive load eliminated the effects of perspective flexibility on judgments. Thus, this interpretation is called into question as well.

A third interpretation of perspective flexibility, although compatible with our conceptualization, is particularly provocative. As an astute reviewer noted, perspective flexibility might be a manifestation of a more general disposition to question one's initial impression of a stimulus, whatever this impression might be, and to consider alternative points of view as well. This interpretation of perspective flexibility has broad implications that extend beyond the domain in which it was applied in this article. For example, it might dispose individuals to question their initial interpretation of a persuasive message and might increase their skepticism of an advertising claim. These possibilities deserve further consideration.

The cultural difference in the support for construal level theory (identified in Experiment 6) is worth noting in this context. To the extent that Asians are generally more flexible in perspective than Westerners (as a consequence of their collectivistic and long-term temporal orientations), their difference from Westerners in other respects might be traceable to this factor. That said, some caution should be taken in overgeneralizing our findings. Although Messervey 
(2008) also found evidence that Asians' construal of events was less influenced by temporal distance than was Westerners' construal, other studies (Kim, Zhang, \& Li, 2008; Yan, 2014; Chen \& Wyer, 2015) have found effects of psychological distance on construal level using Hong Kong Chinese participants. Thus, it would be a mistake to conclude that Asians do not exhibit the effects implied by construal level theory, particularly when they are unmotivated to think extensively about the information they receive (Chen \& Wyer, 2015). The effects of psychological distance among Asians may simply be less strong than it is among Westerners.

In this regard, Messervey (2008) reported a similar interaction between culture and psychological distance on construal level. In interpreting this finding, however, Messervey concluded that Asians are less influenced by psychological distance than Westerners because they are less "flexible," that is, relying generally less on abstract information than Westerners do. In contrast, our research suggests the opposite; that is, Asians are more flexible in terms of the perspective they take. In light of the more general evidence we have obtained of the effects of perspective flexibility, our interpretation seems more viable.

Our findings may also help to understand apparent inconsistencies in the conclusions drawn from previous research. Cousins (1989), for example, suggested that because collectivists see themselves as embedded in social groups, they use a global "lens" to see themselves and their immediate situation. Other research, however, has shown that collectivists are sensitive to contextual variations and consequently process information with lower-level construals (Förster \& Higgins, 2005; Kanagawa, Cross, \& Markus, 2001; Spassova \& Lee, 2013). These different conclusions may reflect the use of different research paradigms. Moreover, the psychological distance of the events being judged was typically not salient. Finally, the research focused largely on the influence of cultural differences on the content of construals (e.g., the level of abstractness of features). The evidence we obtained of the interactive effects of cultural orientation and psychological distance makes salient the influence of cultural differences on the process that people use in forming a representation that contains these features.

\section{References}

Ayduk, O., \& Kross, E. (2008). Enhancing the pace of recovery: Selfdistanced analysis of negative experiences reduces blood pressure reactivity. Psychological Science, 19, 229-231. http://dx.doi.org/10.1111/j .1467-9280.2008.02073.x

Bar-Anan, Y., Liberman, N., \& Trope, Y. (2006). The association between psychological distance and construal level: Evidence from an implicit association test. Journal of Experimental Psychology: General, 135, 609-622. http://dx.doi.org/10.1037/0096-3445.135.4.609

Bearden, W. O., Money, R. B., \& Nevins, J. L. (2006). A measure of long-term orientation: Development and validation. Journal of the Academy of Marketing Science, 34, 456-467. http://dx.doi.org/10.1177/ 0092070306286706

Beldona, S., Inkpen, A. C., \& Phatak, A. (1998). Are Japanese managers more long-term oriented than United States managers? Management International Review, 38, 239-256.

Ben-Itzhak, S., Bluvstein, I., \& Maor, M. (2014). The psychological flexibility questionnaire (PFQ): Development, reliability and validity. WebmedCentral Psychology, 5(4), WMC004606.

Brewer, M. B., \& Gardner, W. (1996). Who is this "We"? Levels of collective identity and self-representations. Journal of Personality and
Social Psychology, 71, 83-93. http://dx.doi.org/10.1037/0022-3514.71 .1 .83

Brislin, R. W., \& Kim, E. S. (2003). Cultural diversity in people's understanding and uses of time. Applied Psychology, 52, 363-382. http://dx .doi.org/10.1111/1464-0597.00140

Bruner, J. S. (1957). Going beyond the information given. In Contemporary approaches to cognition. Cambridge, MA: Harvard University Press.

Chen, F., \& Wyer, R. S., Jr. (2015). The effects of affect, processing goals and temporal distance on information processing: Qualifications on temporal construal theory. Journal of Consumer Psychology, 25, 326332. http://dx.doi.org/10.1016/j.jcps.2014.09.004

Chen, Y., Monaco, S., Byrne, P., Yan, X., Henriques, D. Y., \& Crawford, J. D. (2014). Allocentric versus egocentric representation of remembered reach targets in human cortex. The Journal of Neuroscience, 34, 1251512526. http://dx.doi.org/10.1523/JNEUROSCI.1445-14.2014

Chinese Culture Connection. (1987). Chinese values and the search for culture free dimensions of culture. Journal of Cross-Cultural Psychology, 18, 143-164. http://dx.doi.org/10.1177/0022002187018002002

Christian, B. M., Miles, L. K., Parkinson, C., \& Macrae, C. N. (2013). Visual perspective and the characteristics of mind wandering. Frontiers in Psychology, 4, 699. http://dx.doi.org/10.3389/fpsyg.2013.00699

Cohen, D., \& Gunz, A. (2002). As seen by the other . . . : Perspectives on the self in the memories and emotional perceptions of Easterners and Westerners. Psychological Science, 13, 55-59. http://dx.doi.org/10 1111/1467-9280.00409

Cousins, S. D. (1989). Culture and self-perception in Japan and the United States. Journal of Personality and Social Psychology, 56, 124-131. http://dx.doi.org/10.1037/0022-3514.56.1.124

Davis, M. H., Conklin, L., Smith, A., \& Luce, C. (1996). Effect of perspective taking on the cognitive representation of persons: A merging of self and other. Journal of Personality and Social Psychology, 70, 713-726. http://dx.doi.org/10.1037/0022-3514.70.4.713

De Mooij, M., \& Hofstede, G. (2011). Cross-cultural consumer behavior: A review of research findings. Journal of International Consumer Marketing, 23, 181-192.

Epley, N., Caruso, E., \& Bazerman, M. H. (2006). When perspective taking increases taking: Reactive egoism in social interaction. Journal of Personality and Social Psychology, 91, 872-889. http://dx.doi.org/10.1037/ 0022-3514.91.5.872

Epley, N., Keysar, B., Van Boven, L., \& Gilovich, T. (2004). Perspective taking as egocentric anchoring and adjustment. Journal of Personality and Social Psychology, 87, 327-339.

Escalas, J. E. (2007). Self-referencing and persuasion: Narrative transportation versus analytical elaboration. The Journal of Consumer Research, 33, 421-429. http://dx.doi.org/10.1086/510216

Förster, J., \& Higgins, E. T. (2005). How global versus local perception fits regulatory focus. Psychological Science, 16, 631-636. http://dx.doi.org/ 10.1111/j.1467-9280.2005.01586.x

Galinsky, A. D., \& Moskowitz, G. B. (2000). Perspective-taking: Decreasing stereotype expression, stereotype accessibility, and in-group favoritism. Journal of Personality and Social Psychology, 78, 708-724. http://dx.doi.org/10.1037/0022-3514.78.4.708

Gardner, W. L., Gabriel, S., \& Lee, A. Y. (1999). "I" value freedom, but "we" value relationships: Self-construal priming mirrors cultural differences in judgment. Psychological Science, 10, 321-326. http://dx.doi .org/10.1111/1467-9280.00162

Gilbert, D. T., \& Hixon, J. G. (1991). The trouble of thinking: Activation and application of stereotypic beliefs. Journal of Personality and Social Psychology, 60, 509-517. http://dx.doi.org/10.1037/0022-3514.60.4 .$\underline{509}$

Gilbert, D. T., \& Osborne, R. E. (1989). Thinking backward: Some curable and incurable consequences of cognitive busyness. Journal of Person- 
ality and Social Psychology, 57, 940-949. http://dx.doi.org/10.1037/ 0022-3514.57.6.940

Gilbert, D. T., Pelham, B. W., \& Krull, D. S. (1988). On cognitive busyness: When person perceivers meet persons perceived. Journal of Personality and Social Psychology, 54, 733-740. http://dx.doi.org/10 $.1037 / 0022-3514.54 .5 .733$

Goldstein, N. J., Vezich, I. S., \& Shapiro, J. R. (2014). Perceived perspective taking: When others walk in our shoes. Journal of Personality and Social Psychology, 106, 941-960. http://dx.doi.org/10.1037/a0036395

Gopnik, A., \& Wellman, H. M. (1992). Why the child's theory of mind really is a theory. Mind \& Language, 7, 145-171. http://dx.doi.org/10 $.1111 / \mathrm{j} .1468-0017.1992 . t b 00202 . x$

Green, M. C., \& Brock, T. C. (2000). The role of transportation in the persuasiveness of public narratives. Journal of Personality and Social Psychology, 79, 701-721. http://dx.doi.org/10.1037/0022-3514.79.5.701

Hayes, A. F. (2013). Introduction to mediation, moderation, and conditional process analysis: A regression-based approach. New York, NY: Guilford Press.

Hofstede, G. (1991). Cultures and organizations: Software of the mind. London, United Kingdom: McGraw-Hill.

Hofstede, G. (2001). Culture's consequences: Comparing values, behaviors, institutions, and organizations across nations. Thousand Oaks, CA: Sage.

Hofstede, G., \& Bond, M. H. (1988). The Confucius connection: From cultural roots to economic growth. Organizational Dynamics, 16, 5-21. http://dx.doi.org/10.1016/0090-2616(88)90009-5

Holland, R. W., Roeder, U. R., van Baaren, R. B., Brandt, A. C., \& Hannover, B. (2004). Don't stand so close to me: The effects of selfconstrual in interpersonal closeness. Psychological Science, 15, $237-$ 242. http://dx.doi.org/10.1111/j.0956-7976.2004.00658.x

Hung, I. W., \& Wyer, R. S., Jr. (2014). Effects of self-relevant perspectivetaking on the impact of persuasive appeals. Personality and Social Psychology Bulletin, 40, 402-414. http://dx.doi.org/10.1177/ 0146167213513474

Jones, E. E., \& Nisbet, R. E. (1972). The actor and the observer: Divergent perceptions of the causes of behavior. In E. E. Jones, D. E. Kanouse, H. H. Kelley, R. E. Nisbett, S. Valins, \& B. Weiner (Eds.), Attribution: Perceiving the causes of behavior (pp. 79-94). Morristown, NJ: General Learning Press.

Kanagawa, C., Cross, S. E., \& Markus, H. R. (2001). "Who am I?" The cultural psychology of the conceptual self. Personality and Social Psychology Bulletin, 27, 90-103. http://dx.doi.org/10.1177/014616 $\underline{7201271008}$

Kemmelmeier, M. (2003). Individualism and attitudes toward affirmative action: Evidence from priming experiments. Basic and Applied Social Psychology, 25, 111-119. http://dx.doi.org/10.1207/ S15324834BASP2502_2

Kim, K., Zhang, M., \& Li, X. (2008). Effects of temporal and social distance on consumer evaluations. The Journal of Consumer Research, 35, 706-713. http://dx.doi.org/10.1086/592131

Kim, Y. J., Park, J., \& Wyer, R. S., Jr. (2009). Effects of temporal distance and memory on consumer judgments. The Journal of Consumer Research, 36, 634-645. http://dx.doi.org/10.1086/599765

Kitayama, S., Markus, H., Tummala, P., Kurokawa, M., \& Kato, K. (1990). Culture and self-cognition. Unpublished manuscript.

Kopalle, P. K., Lehmann, D. R., \& Farley, J. U. (2010). Consumer expectations and culture: The effect of belief in karma in India. The Journal of Consumer Research, 37, 251-263. http://dx.doi.org/10.1086/ 651939

Kross, E., \& Ayduk, O. (2008). Facilitating adaptive emotional analysis: Distinguishing distanced-analysis of depressive experiences from immersed-analysis and distraction. Personality and Social Psychology Bulletin, 34, 924-938. http://dx.doi.org/10.1177/0146167208315938
Kross, E., Ayduk, O., \& Mischel, W. (2005). When asking "why" does not hurt. Distinguishing rumination from reflective processing of negative emotions. Psychological Science, 16, 709-715. http://dx.doi.org/10 .1111/j.1467-9280.2005.01600.x

Kross, E., Bruehlman-Senecal, E., Park, J., Burson, A., Dougherty, A., Shablack, H., . . . Ayduk, O. (2014). Self-talk as a regulatory mechanism: How you do it matters. Journal of Personality and Social Psychology, 106, 304-324. http://dx.doi.org/10.1037/a0035173

Kross, E., \& Grossmann, I. (2012). Boosting wisdom: Distance from the self enhances wise reasoning, attitudes, and behavior. Journal of Experimental Psychology: General, 141, 43-48. http://dx.doi.org/10.1037/ a0024158

Kühnen, U., Hannover, B., \& Schubert, B. (2001). The semanticProcedural interface model of the self: The role of self-knowledge for context-dependent versus context-independent modes of thinking. Journal of Personality and Social Psychology, 80, 397-409.

Kühnen, U., \& Oyserman, D. (2002). Thinking about the self influences thinking in general: Cognitive consequences of salient self-concept. Journal of Experimental Social Psychology, 38, 492-499. http://dx.doi .org/10.1016/S0022-1031(02)00011-2

Lastovicka, J. L., Bettencourt, L. A., Hughner, R. S., \& Kuntze, R. J. (1999). Lifestyle of the tight and frugal: Theory and measurement. The Journal of Consumer Research, 26, 85-98. http://dx.doi.org/10.1086/ 209552

Lee, A. Y., Aaker, J. L., \& Gardner, W. L. (2000). The pleasures and pains of distinct self-construals: The role of interdependence in regulatory focus. Journal of Personality and Social Psychology, 78, 1122-1134. http://dx.doi.org/10.1037/0022-3514.78.6.1122

Libby, L. K., Shaeffer, E. M., \& Eibach, R. P. (2009). Seeing meaning in action: A bidirectional link between visual perspective and action identification level. Journal of Experimental Psychology: General, 138, 503-516. http://dx.doi.org/10.1037/a0016795

Liberman, N., \& Förster, J. (2009). Distancing from experienced self: How global-versus-local perception affects estimation of psychological distance. Journal of Personality and Social Psychology, 97, 203-216. http://dx.doi.org/10.1037/a0015671

Liberman, N., Sagristano, M. D., \& Trope, Y. (2002). The effect of temporal distance on level of mental construal. Journal of Experimental Social Psychology, 38, 523-534. http://dx.doi.org/10.1016/S00221031(02)00535-8

Liberman, N., \& Trope, Y. (1998). The role of feasibility and desirability considerations in near and distant future decisions: A test of temporal construal theory. Journal of Personality and Social Psychology, 75, 5-18. http://dx.doi.org/10.1037/0022-3514.75.1.5

Liberman, N., \& Trope, Y. (2008). The psychology of transcending the here and now. Science, 322, 1201-1205. http://dx.doi.org/10.1126/ science.1161958

Maddux, W. W., \& Yuki, M. (2006). The "ripple effect": Cultural differences in perceptions of the consequences of events. Personality and Social Psychology Bulletin, 32, 669-683. http://dx.doi.org/10.1177/ $\underline{0146167205283840}$

McFerran, B., Dahl, D. W., Gorn, G. J., \& Honea, H. (2010). Motivational determinants of transportation into marketing narratives. Journal of Consumer Psychology, 20, 306-316. http://dx.doi.org/10.1016/j.jcps 2010.06.017

Messervey, D. L. (2008). Time and time again: Cultural differences in construal levels (Unpublished doctoral dissertation) Queen's University.

Milfont, T. L., \& Gouveia, V. V. (2006). Time perspective and values: An exploratory study of their relations to environmental attitudes. Journal of Environmental Psychology, 26, 72-82. http://dx.doi.org/10.1016/j.jenvp 2006.03.001

Oyserman, D., Coon, H. M., \& Kemmelmeier, M. (2002). Rethinking individualism and collectivism: Evaluation of theoretical assumptions and meta-analyses. Psychological Bulletin, 128, 3-72. 
Oyserman, D., \& Lee, S. W. S. (2008). Does culture influence what and how we think? Effects of priming individualism and collectivism. Psychological Bulletin, 134, 311-342. http://dx.doi.org/10.1037/0033-2909 .134 .2 .311

Oyserman, D., \& Sorensen, N. (2009). Understanding cultural syndrome effects on what and how we think. In R. S. Wyer, C. Y. Chiu, \& Y. Y. Hong (Eds.), Understanding culture: Theory, research, and application (pp. 25-52). New York, NY: Psychology Press.

Paolacci, G., Chandler, J., \& Ipeirotis, P. G. (2010). Running experiments on Amazon Mechanical Turk. Judgment and Decision Making, 5, 411419.

Pronin, E., Olivola, C. Y., \& Kennedy, K. A. (2008). Doing unto future selves as you would do unto others: Psychological distance and decision making. Personality and Social Psychology Bulletin, 34, 224-236. http://dx.doi.org/10.1177/0146167207310023

Radvansky, G. A., \& Zacks, R. T. (1991). Mental models and the fan effect. Journal of Experimental Psychology: Learning, Memory, and Cognition, 17, 940-953. http://dx.doi.org/10.1037/0278-7393.17.5.940

Ross, M., Xun, W. Q. E., \& Wilson, A. E. (2002). Language and the bicultural self. Personality and Social Psychology Bulletin, 28, 10401050. http://dx.doi.org/10.1177/01461672022811003

Seih, Y. T., Buhrmester, M. D., Lin, Y. C., Huang, C. L., \& Swann, W. B., Jr. (2013). Do people want to be flattered or understood? The crosscultural universality of self-verification. Journal of Experimental Social Psychology, 49, 169-172. http://dx.doi.org/10.1016/j.jesp.2012.09.004

Singelis, T. M., Triandis, H. C., Bhawuk, D. P. S., \& Gelfand, M. J. (1995). Horizontal and vertical dimensions of individualism and collectivism: A theoretical and measurement refinement. Cross-Cultural Research: The Journal of Comparative Social Science, 29, 240-275. http://dx.doi.org/ 10.1177/106939719502900302

Slabu, L., Lenton, A. P., Sedikides, C., \& Bruder, M. (2014). Trait and state authenticity across cultures. Journal of Cross-Cultural Psychology, 45, 1347-1373. http://dx.doi.org/10.1177/0022022114543520

Soderberg, C. K., Callahan, S. P., Kochersberger, A. O., Amit, E., \& Ledgerwood, A. (2015). The effects of psychological distance on abstraction: Two meta-analyses. Psychological Bulletin, 141, 525-548. http://dx.doi.org/10.1037/bul0000005

Spassova, G., \& Lee, A. Y. (2013). Looking into the future: A match between self-view and temporal distance. The Journal of Consumer Research, 40, 159-171. http://dx.doi.org/10.1086/669145

Sujan, M., Bettman, J. R., \& Baumgartner, H. (1993). Influencing consumer judgments using autobiographical memories: A self-referencing perspective. Journal of Marketing Research, 30, 422-436. http://dx.doi .org/10.2307/3172688

Trafimow, D., Triandis, H. C., \& Goto, S. G. (1991). Some tests of the distinction between the private self and the collective self. Journal of Personality and Social Psychology, 60, 649-655. http://dx.doi.org/10 $.1037 / 0022-3514.60 .5 .649$

Triandis, H. C. (1995). Individualism and collectivism. Boulder, CO: Westview.
Trope, Y., \& Liberman, N. (2003). Temporal construal. Psychological Review, 110, 403-421. http://dx.doi.org/10.1037/0033-295X.110.3.403

Trope, Y., \& Liberman, N. (2010). Construal-level theory of psychological distance. Psychological Review, 117, 440-463. http://dx.doi.org/10 $.1037 / \mathrm{a} 0018963$

Trope, Y., Liberman, N., \& Wakslak, C. (2007). Construal levels and psychological distance: Effects on representation, prediction, evaluation, and behavior. Journal of Consumer Psychology, 17, 83-95. http://dx.doi .org/10.1016/S1057-7408(07)70013-X

Vohs, K. D., \& Heatherton, T. F. (2001). Self-Esteem and threats to self: Implications for self-construals and interpersonal perceptions. Journal of Personality and Social Psychology, 81, 1103-1118. http://dx.doi.org/10 .1037/0022-3514.81.6.1103

Wu, S., \& Keysar, B. (2007). The effect of culture on perspective taking. Psychological Science, 18, 600-606. http://dx.doi.org/10.1111/j.14679280.2007.01946.x

Wyer, R. S. (2003). Social comprehension and judgment: The role of situation models, narratives, and implicit theories. Psychology Press.

Wyer, R. S., \& Radvansky, G. A. (1999). The comprehension and validation of social information. Psychological Review, 106, 89-118. http:// dx.doi.org/10.1037/0033-295X.106.1.89

Wyer, R. S., \& Xu, A. J. (2010). The role of behavioral mind-sets in goal-directed activity: Conceptual underpinnings and empirical evidence. Journal of Consumer Psychology, 20, 107-125. http://dx.doi.org/ 10.1016/j.jcps.2010.01.003

Wyer, R. S., Xu, A. J., \& Shen, H. (2012). The effects of past behavior on future goal-directed activity. Advances in Experimental Social Psychology, 46, 237-284. http://dx.doi.org/10.1016/B978-0-12-394281-4 $.00014-3$

Yan, D. (2014). Future events are far away: Exploring the distance-ondistance effect. Journal of Personality and Social Psychology, 106, 514-525. http://dx.doi.org/10.1037/a0036066

Yan, D., \& Sengupta, J. (2011). Effects of construal level on the pricequality relationship. The Journal of Consumer Research, 38, 376-389. http://dx.doi.org/10.1086/659755

Ybarra, O., \& Trafimow, D. (1998). How priming the private self or collective self affects the relative weights of attitudes and subjective norms. Personality and Social Psychology Bulletin, 24, 362-370. http:// dx.doi.org/10.1177/0146167298244003

Zhang, M., \& Wang, J. (2009). Psychological distance asymmetry: The spatial dimension vs. other dimensions. Journal of Consumer Psychology, 19, 497-507. http://dx.doi.org/10.1016/j.jcps.2009.05.001

Zhao, M., Hoeffler, S., \& Zauberman, G. (2007). Mental simulation and preference consistency over time: The role of process-versus outcomefocused thoughts. Journal of Marketing Research, 44, 379-388. http:// dx.doi.org/10.1509/jmkr.44.3.379

Zimbardo, P. G., \& Boyd, J. N. (1999). Putting time in perspective: A valid, reliable individual-differences metric. Journal of Personality and Social Psychology, 77, 1271-1288. http://dx.doi.org/10.1037/0022-3514 .77.6.1271 


\section{Appendix A}

\section{Reading Materials of the "Defense Game" in Experiment 1}

\section{The Flight Delay Case}

Now imagine the following situation that concerns a flight delay. Three parties, (a) an airport, (b) Airline Company A, and (c) the passengers, were involved.

The airport was suffering from bad weather conditions. To maintain equity, the airport management department proposed a traffic control system that would permit the planes of each airline company take turns taking off. However, because of the airport's poor implementation of the policy and the inexperience of some traffic controllers, an error was made and the planes of a particular airline, A, were unreasonably delayed. The staff of Company A, frustrated by the situation, failed to communicate adequately with the passengers and responded impolitely and often aggressively to questions and complaints, refusing to provide information about the situation at hand. Consequently, some passengers became very angry and physically assaulted some of the airline staff and tore up the waiting area, damaging the facilities and creating chaos that created further delays in other airlines as well. As a result, the airport, the airline company, and the passengers all encountered a financial loss and claimed reimbursement for damages.

\section{Appendix B}

\section{Descriptions of the Apartment Stimuli}

\section{Experiments 1, 2a, and 3a}

Please imagine that you are looking for a new apartment to move into now/1 year later, and have found an apartment available.

Suppose the apartment has the following advantages:

(1) Large living space

(2) Bed, TV set, and desk will be provided

But it also has the following disadvantages:

(1) Inflexible moving-in date

(2) The moving expense is high

\section{Experiments 2b and $3 b$}

Please imagine that you are looking for a new apartment to move into now/1 year later, and have found an apartment available.
Suppose the apartment has the following advantages:

(1) Flexible moving-in date

(2) Low moving expense

But it also has the following disadvantages:

(1) Limited living space

(2) Bed, TV set, and desk not included
Received November 4, 2015 Revision received February 12, 2016 Accepted February 12, 2016 